Check for updates

Cite this: RSC Adv., 2020, 10, 18519

Received 17th April 2020

Accepted 28th April 2020

DOI: 10.1039/d0ra03444d

rsc.li/rsc-advances

\section{Theoretical perspective on the electronic structure and photophysical properties for a series of mixed- carbene tris-cyclometalated iridium(III) complexes $\uparrow$}

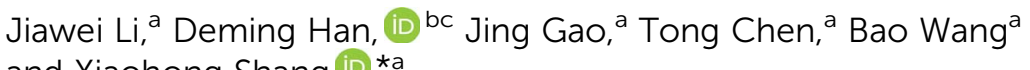 \\ and Xiaohong Shang (D) *a
}

The electronic structure and photophysical properties of four mixed-carbene tris-cyclometalated iridium(III) complexes have been theoretically investigated by the density functional theory (DFT) and time-dependent density functional theory (TDDFT) methods. The effect of varying the main ligand by introducing different ring structures on the photophysical properties of the studied complexes has been explored. All studied complexes have slightly distorted octahedral geometries. The complex with a rigid skeletal structural main ligand possesses the smallest difference between the recombination energy of hole transport and recombination energy of electron transport among these complexes, enhancing the charge transfer balance. The lowest energy emission wavelength calculated is in very good agreement with the available experimental value. This study will provide useful information for the design of new phosphorescent organic light-emitting diode (OLED) materials.
\end{abstract}

\section{Introduction}

Nowadays, organic light-emitting diodes (OLEDs) have attracted great interest from researchers due to their potential applications as light-emitting materials and the next generation materials of flat panel displays. ${ }^{1-3}$ Transition metal phosphorescent complexes, such as $\mathrm{Ru}(\mathrm{II}), \mathrm{Rh}(\mathrm{III}), \mathrm{Cu}(\mathrm{I}), \mathrm{Os}(\mathrm{II}), \operatorname{Ir}(\mathrm{III})$ and Pt(II) complexes, have been successfully applied to OLEDs, electrochemiluminescence, dye-sensitized solar cells, photocatalysis and so on. ${ }^{4-9}$ Especially, iridium(III)-based phosphorescent complexes have attracted great attention due to their potential practical applications in OLEDs, and they have high emission quantum yields, short excited triplet state lifetimes and photochemical stability. ${ }^{10-15}$ Phosphorescent transition metal complexes can harvest both singlet and triplet excitons due to their effective intersystem crossing (ISC) and achieve an internal quantum efficiency as high as $100 \%$, which breaks the $25 \%$ theoretical internal quantum efficiency limitation predicted in fluorescent devices based on singlet exciton emission. $^{16,17}$

${ }^{a}$ College of Chemistry and Life Science, Changchun University of Technology, Changchun 130012, P. R. China. E-mail: shangxiaohong58@aliyun.com

${ }^{b}$ School of Life Science and Technology, Changchun University of Science and Technology, Changchun 130022, P. R. China

Jilin Provincial Science and Technology Innovation Center of Optical Materials and Chemistry, Changchun, 130022, P. R. China

$\dagger$ Electronic supplementary information (ESI) available. See DOI: $10.1039 /$ d0ra03444d

It is known that the good selection of chelates with distinctive electronic and steric properties is very important in the design strategy, which chelates are one key factor in assembling

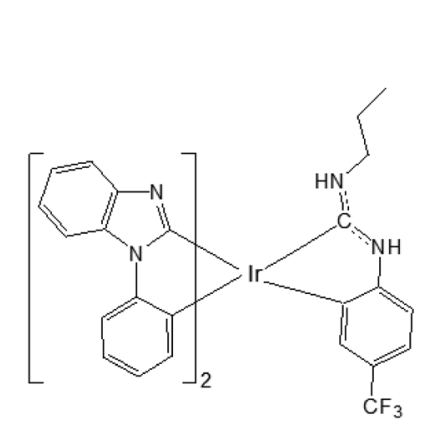

1

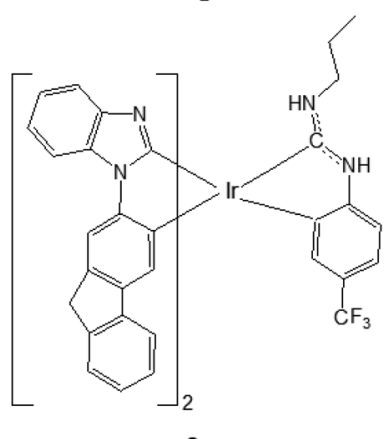

3

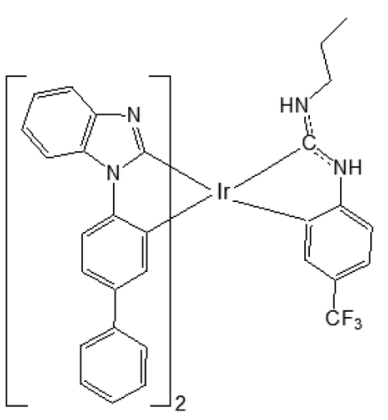

2

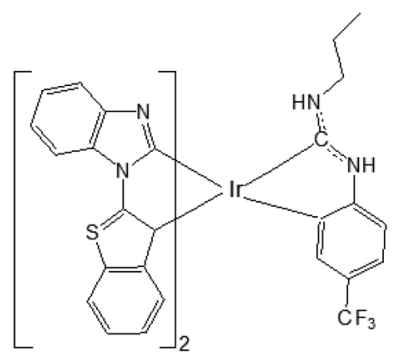

4
Fig. 1 Schematic structures of complexes 1-4. 
luminescent metal complexes. The luminescence spectra of iridium(III) complexes can be tuned from near ultraviolet to visible and near infrared regions by the method of chemical modification and functionalization of the ligands. Hanah $\mathrm{Na}$ et al. have designed a new class of hybrid carbene ring metallated iridium complexes $\left[\operatorname{Ir}\left(\mathrm{C}^{\wedge} \mathrm{C}^{\mathrm{NHC}}\right)_{2}\left(\mathrm{C}^{\wedge} \mathrm{C}:{ }^{\mathrm{ADC}}\right)\right]$, which emit blue light and have good photoluminescence quantum yield, ${ }^{18}$ Herein, on the basis of the experimental complex $3 b^{\mathbf{1 8}}$ (named as 1 in Fig. 1), three iridium(III) complexes have been designed. By using the density functional theory (DFT) and timedependent density functional theory (TDDFT) method, the electronic structure and photophysical properties for these complexes have been theoretically studied. It is anticipated that the study will provide useful information for the designing of new phosphorescent OLEDs material.

\section{Computational methods}

The ground-state and the lowest-lying triplet excited-state geometries were optimized by density functional theory (DFT) method $^{\mathbf{1 9}}$ with hybrid Hartree-Fock/density functional model (PBE0) based on the Perdew-Burke-Ernzerhof (PBE) approach, ${ }^{20,21}$ respectively. All geometrical structures were fully optimized without any symmetry constraints. Vibrational frequencies were also calculated at the same theoretical level to confirm that each configuration was a minimum on the potential energy surface. On the basis of the optimized groundand excited-state geometry structures, the time-dependent DFT (TDDFT) approach associated with the polarized continuum model (PCM $)^{22}$ in dichloromethane $\left(\mathrm{CH}_{2} \mathrm{Cl}_{2}\right)$ media was applied to investigate the absorption and emission spectral properties.

In the calculations, the quasi-relativistic pseudo-potential of Ir atom proposed by Hay and Wadt with 17 valence electrons was used, and a "double- $\xi$ " quality basis set LANL2DZ was adopted. ${ }^{23,24}$ The 6-31G* basis set was employed on non-metal atoms in the gradient optimizations. The above-mentioned methods and basis sets for transition metal complexes have supported their reliability and gave good agreement with experimental results. ${ }^{25-27}$ The properties of the $\operatorname{Ir}(\mathrm{III})$ complexes, such as ionization potential (IP), electron affinity (EA), reorganization energy $(\lambda)$, etc. were also calculated by the method mentioned above. For all calculations, the Gaussian 09 software package of programs ${ }^{28}$ was performed. The absorption spectra were simulated by using GaussSum program Rev. 2.5 (ref. 29) based on the data obtained via TDDFT calculations.

\section{Results and discussion}

\subsection{Molecular geometries in ground and lowest triplet states}

The sketch map of iridium(III) complexes 1-4 are presented in Fig. 1. The optimized ground state geometric structure for complex 1 is also shown in Fig. 2 along with the numbering of some key atoms. The optimized geometry parameters of 1-4 in the ground and lowest triplet states $\left(\mathrm{T}_{1}\right)$ are listed in Table 1.

These complexes have the general structure $\operatorname{Ir}(\mathrm{L} 1)_{2} \mathrm{~L} 2$, where L1 is an N-heterocyclic carbene (NHC) and L2 is cyclometalating ligand featuring an acyclic diaminocarbene (ADC). The

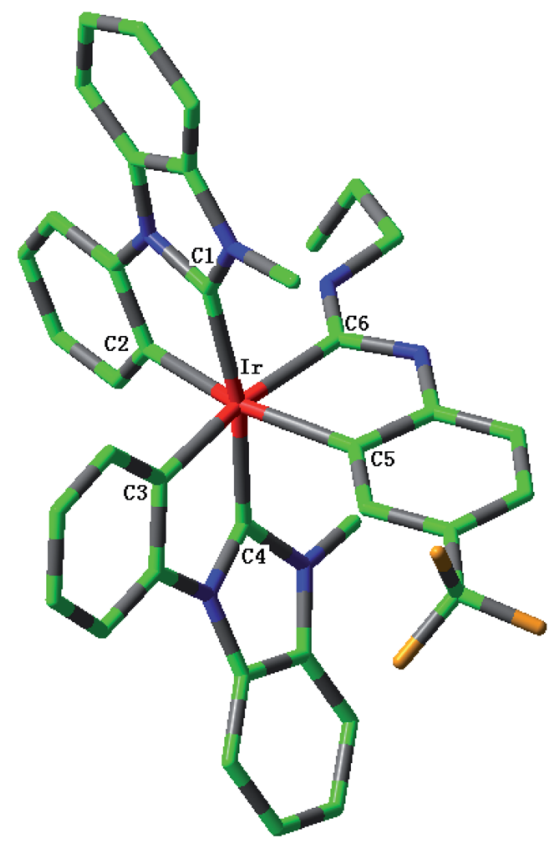

Fig. 2 Optimized geometry structure of complex 1 in the ground state ( $\mathrm{H}$ atoms omitted).

optimized ground state geometric structure for complex $\mathbf{1}$ is good agreement with the single-crystal X-ray structure. ${ }^{18}$ The maximum deviation between the calculated bond lengths and the experimental values is $0.017 \AA$, which indicates the theoretical method is reliable. The bond angles C1-Ir-C2 (C3-Ir-C4, C5-Ir-C6) and C1-Ir-C4 (C2-Ir-C5, C3-Ir-C6) are close to $80^{\circ}$ and $170^{\circ}$, respectively, which shows that complexes 1-4 adopt a pseudo-octahedral coordination geometry. In addition, the dihedral angles $\mathrm{C} 1-\mathrm{C} 2-\mathrm{C} 4-\mathrm{C} 5$ and $\mathrm{C} 1-\mathrm{C} 3-\mathrm{C} 4-\mathrm{C} 6$ for complexes 1-4 are between $8^{\circ}$ and $16^{\circ}$. The C2-C3-C5-C6 for complexes 14 are smaller than $3^{\circ}$, especially, those of 1, 2 and 3 are near to $1^{\circ}$, which shows that there is a plane structure around the central Ir atom. Upon excitation to the $\mathrm{T}_{1}$ state, complexes 1-4 basically retain their geometries with slightly changed bond lengths and bond angles around the iridium center.

\subsection{Frontier molecular orbital (FMOs) properties}

Since the optical and chemical properties of these complexes are closely related to the electronic structure of their ground state, the properties of the Frontier molecular orbitals (FMOs) of these complexes are investigated in detail in this section. The distribution of HOMO and LUMO, energy level, and the energy gap between HOMO-LUMO $\left(\Delta E_{\mathrm{L} \rightarrow \mathrm{H}}\right)$ are shown in Fig. 3. The Frontier FMO compositions of all studied complexes are listed in Tables S1-S4 (ESI). $\dagger$

The LUMO for complexes 1-4 mainly reside on the L1 main ligand. For example, for complex 1, the LUMO has the distribution with L1 ligand $94 \% \pi *$-orbital. The HOMO for complexes 1-4 are mainly localized at Ir d-orbital and L1 main ligand. For example, the LUMO of 1 has $36 \%$ Ir $5 \mathrm{~d}$ orbital and $57 \% \pi$ orbital. It is known that the tuning emission color by changing substituents relies on the fact that the lowest excited state is 
Table 1 Main optimized geometry parameters of complexes 1-4 in the ground and the lowest lying triplet states, together with the experimental values

\begin{tabular}{|c|c|c|c|c|c|c|c|c|}
\hline & \multicolumn{2}{|l|}{1} & \multicolumn{2}{|l|}{2} & \multicolumn{2}{|l|}{3} & \multicolumn{2}{|l|}{4} \\
\hline & $\mathrm{S}_{0} / \operatorname{exptl}^{a}$ & $\mathrm{~T}_{1}$ & $\mathrm{~S}_{0}$ & $\mathrm{~T}_{1}$ & $\mathrm{~S}_{0}$ & $\mathrm{~T}_{1}$ & $\mathrm{~S}_{0}$ & $\mathrm{~T}_{1}$ \\
\hline $\mathrm{Ir}-\mathrm{C} 1$ & $2.035 / 2.026$ & 2.043 & 2.035 & 2.035 & 2.033 & 2.033 & 2.054 & 2.054 \\
\hline $\mathrm{Ir}-\mathrm{C} 2$ & $2.085 / 2.096$ & 2.078 & 2.087 & 2.072 & 2.087 & 2.064 & 2.063 & 2.066 \\
\hline $\mathrm{Ir}-\mathrm{C} 3$ & $2.075 / 2.081$ & 2.009 & 2.074 & 2.074 & 2.078 & 2.078 & 2.048 & 2.049 \\
\hline Ir-C6 & $2.056 / 2.019$ & 2.104 & 2.056 & 2.060 & 2.056 & 2.061 & 2.055 & 2.068 \\
\hline \multicolumn{9}{|l|}{ Bond angle $\left({ }^{\circ}\right)$} \\
\hline $\mathrm{C} 1-\mathrm{Ir}-\mathrm{C} 2$ & $78.04 / 77.82$ & 78.30 & 78.02 & 79.14 & 78.07 & 79.19 & 76.80 & 76.80 \\
\hline $\mathrm{C} 3-\mathrm{Ir}-\mathrm{C} 4$ & $78.12 / 77.70$ & 79.23 & 78.13 & 78.22 & 77.97 & 78.03 & 76.74 & 77.78 \\
\hline $\mathrm{C} 5-\mathrm{Ir}-\mathrm{C} 6$ & $78.62 / 79.57$ & 77.20 & 78.63 & 78.54 & 78.63 & 78.49 & 78.66 & 78.16 \\
\hline \multicolumn{9}{|c|}{ Dihedral angle $\left({ }^{\circ}\right)$} \\
\hline $\mathrm{C} 1-\mathrm{C} 2-\mathrm{C} 4-\mathrm{C} 5$ & $15.11 / 12.32$ & 17.28 & 14.84 & 15.54 & 15.35 & 15.81 & 15.73 & 16.19 \\
\hline C1-C3-C4-C6 & $10.38 / 10.03$ & 11.96 & 10.93 & 10.78 & 10.51 & 9.91 & 8.35 & 11.54 \\
\hline C2-C3-C5-C6 & $0.80 / 3.81$ & 0.51 & 0.88 & 0.88 & 0.76 & 0.76 & 2.52 & 1.72 \\
\hline
\end{tabular}

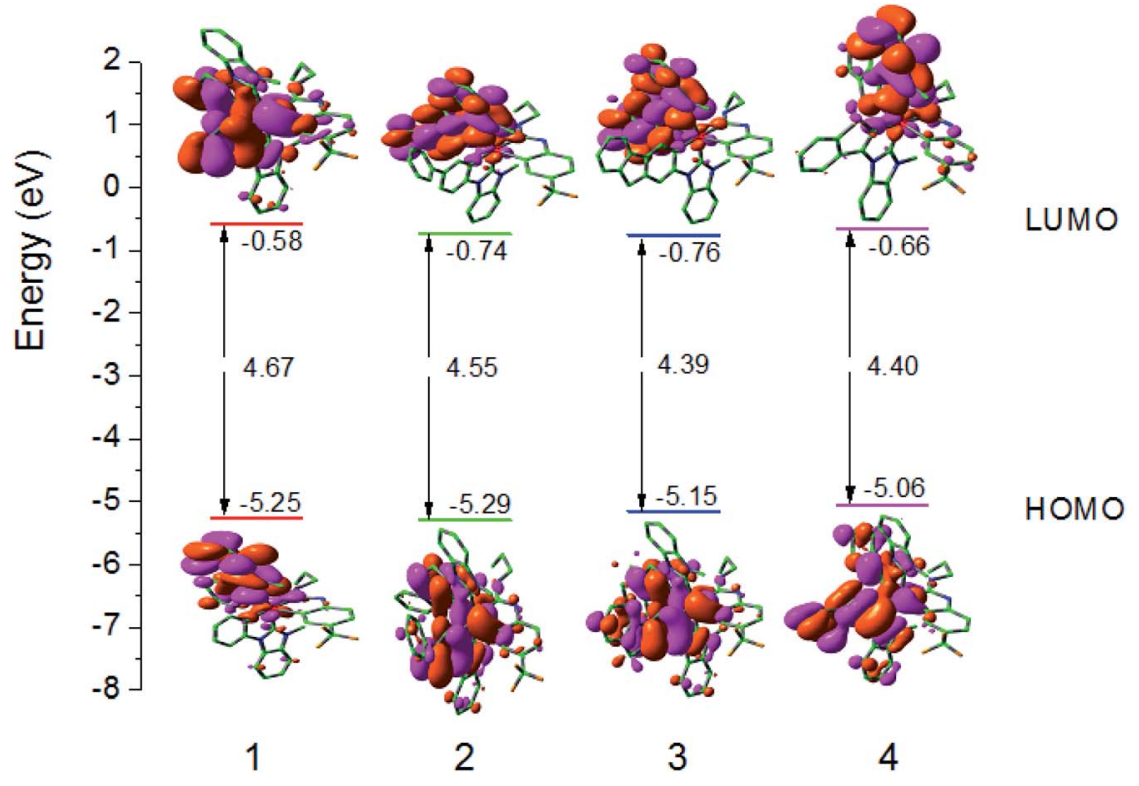

Fig. 3 Molecular orbital diagrams and HOMO and LUMO energies for complexes 1-4.

relatively well described as a transition from HOMO to LUMO in a given ligand. Hence, to investigate the $\Delta E_{\mathrm{L} \rightarrow \mathrm{H}}$ can give some useful information on the variation trend of absorption and emission spectra. In comparison with those of $\mathbf{1}$, the LUMO energy levels of complexes 2-4 are decreased. In contrast to 2 , the HOMO and LUMO energy levels of 3 with rigid ligand are increased and decreased, respectively. The $\Delta E_{\mathrm{L} \rightarrow \mathrm{H}}$ values of 1 and $\mathbf{3}$ are the largest and smallest ones, respectively, among all studied complexes, which indicates that enhancing the conjugated degree by changing the main ligand can reduce the $\Delta E_{\mathrm{L} \rightarrow}$ $\mathrm{H}$ values.

\subsection{Ionization potential (IP) and electronic affinity (EA)}

The performance of an OLED device is closely associated with IP, EA and migration of charge. IP and EA can be used to predict the energy barrier of holes and electrons. The size of IP and EA 
Table 2 The calculated vertical IP $\left(I_{\mathrm{v}}\right)$, adiabatic IP $\left(\mathrm{IP}_{\mathrm{a}}\right)$, hole extraction potential $(H E P)$, vertical $E A\left(E A_{v}\right)$, adiabatic $E A\left(E A_{a}\right)$, electron extraction potential (EEP), reorganization energies for electrons $\left(\lambda_{\mathrm{e}}\right)$ and holes $\left(\lambda_{\mathrm{h}}\right)$, and $\Delta=\left|\lambda_{\mathrm{h}}-\lambda_{\mathrm{e}}\right|$ (in eV) for complexes 1-4

\begin{tabular}{lccccccccc}
\hline & $\mathrm{IP}_{\mathrm{v}}$ & $\mathrm{IP}_{\mathrm{a}}$ & $\mathrm{HEP}$ & $\mathrm{EA}_{\mathrm{v}}$ & $\mathrm{EA}_{\mathrm{a}}$ & $\mathrm{EEP}$ & $\lambda_{\mathrm{h}}$ & $\lambda_{\mathrm{e}}$ & $\Delta$ \\
\hline $\mathbf{1}$ & 5.07 & 4.84 & 4.58 & 0.70 & 0.88 & 1.15 & 4.91 & 0.70 & 4.21 \\
$\mathbf{2}$ & 5.11 & 4.89 & 4.65 & 0.86 & 1.07 & 1.29 & 4.94 & 0.86 & 4.08 \\
$\mathbf{3}$ & 4.98 & 4.79 & 4.57 & 0.89 & 1.01 & 1.15 & 4.81 & 0.89 & 3.92 \\
$\mathbf{4}$ & 4.91 & 4.75 & 4.59 & 0.79 & 1.00 & 1.43 & 4.74 & 0.79 & 3.95
\end{tabular}

is related to the HOMO and LUMO levels of the complex. The IP and EA can be either for vertical excitations (v; at the geometry of neutral molecule) or adiabatic excitations ( $\mathrm{a}$; optimized structure for both the neutral and charged molecules). Generally, a smaller IP value means easier hole injection ability and a larger EA value will facilitate electron injection. We have calculated the hole extraction potential (HEP), which is the energy difference between $\mathbf{M}$ (neutral molecule) and $\mathbf{M}^{+}$ (cationic), using $\mathrm{M}^{+}$geometry, and electron extraction potential (EEP), which is the energy difference between $\mathrm{M}^{-}$and $\mathbf{M}^{-}$ (anionic), using $\mathrm{M}^{-}$geometry. The calculated vertical IP $\left(\mathrm{IP}_{\mathrm{v}}\right)$, adiabatic IP (IP $P_{a}$, vertical EA $\left(\mathrm{EA}_{\mathrm{v}}\right)$, adiabatic EA $\left(\mathrm{EA}_{\mathrm{a}}\right), \mathrm{HEP}$, and EEP are listed in Table 2.

The IP values of $\mathbf{4}$ the smallest ones among these studied complexes, indicating that its hole injection energy barrier is the lowest, which is also consistent with its highest HOMO energy level. Complexes $\mathbf{2}$ and $\mathbf{3}$ have the larger EA values, so their electron injection is relatively easy compared to other complexes, which is consistent with their lowest LUMO energy level. The EA values of $\mathbf{1}$ are the smallest one, which will lead to an increased electron injection energy barrier. According to the semi-empirical Marcus model, ${ }^{30-32}$ the transfer rate of charge (holes and electrons) $K_{\text {et }}$ can be expressed by the following formula:

$$
K_{\text {et }}=A \exp \left(-\lambda / 4 K_{\mathrm{B}} T\right)
$$

Among them, $\lambda$ is the recombination energy, $A$ is the electron coupling correlation factor between adjacent complexes, and $T$ and $K_{\mathrm{B}}$ are the temperature and Boltzmann constant, respectively. Due to the limited intermolecular charge transfer range in the solid state, the mobility of charges has been demonstrated to be predominantly related to the internal reorganization energy $\lambda$ for OLEDs materials. ${ }^{33,34}$ According to the formula (1), at a certain temperature, the smaller the $\lambda$ value, the faster the charge transfer rate. In general, the value of the recombination energy $\lambda$ is mainly determined by two aspects: internal recombination energy $\left(\lambda_{\mathrm{i}}\right)$ and external recombination energy $\left(\lambda_{\mathrm{e}}\right)$. The external recombination energy can mainly come from the polarization effect of the surrounding medium, and in the solid-state optoelectronic device, the external recombination energy of the luminescent material can be neglected. Therefore, here we will mainly discuss the internal recombination energy of the complex. Internal recombination energy refers to the energy change caused by the rapid change of molecular geometry, which is caused by the change of internal nuclear

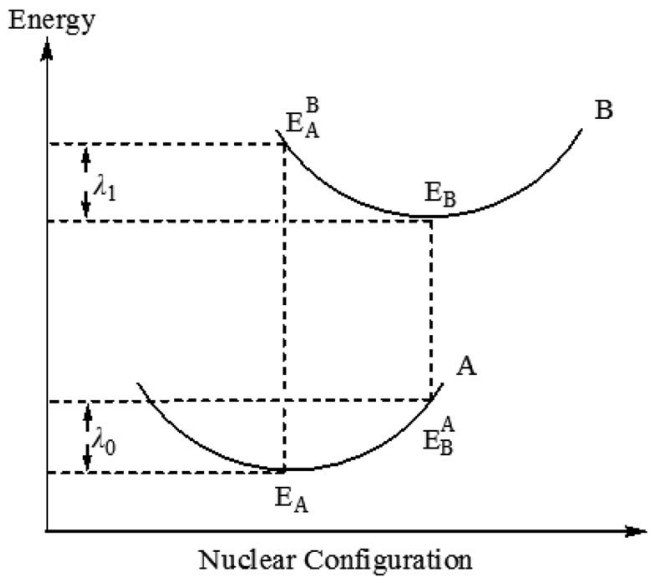

Fig. 4 Schematic description of the inner reorganization energy.

coordinates from the reactant A to the product B and vice versa (Fig. 4), which is mainly the sum of two relaxation energies:

$$
\lambda_{\mathrm{i}}=\lambda_{0}+\lambda_{1}=\left(E_{\mathrm{B}}^{\mathrm{A}}-E_{\mathrm{A}}\right)+\left(E_{\mathrm{A}}^{\mathrm{B}}-E_{\mathrm{B}}\right)
$$

where $E_{\mathrm{A}}$ and $E_{\mathrm{A}}^{\mathrm{B}}$ are the energies of $\mathrm{A}$ and B at the optimized geometry of A, respectively; while $E_{\mathrm{B}}^{\mathrm{A}}$ and $E_{\mathrm{B}}$ are the energies of A and $\mathrm{B}$ at the optimized geometry of $\mathrm{B}$, respectively. As can be seen from Fig. 4, the recombination energy of hole transport $\left(\lambda_{\mathrm{h}}\right)$ and electron transport $\left(\lambda_{\mathrm{e}}\right)$ can be expressed by the following formula:

$$
\begin{aligned}
& \lambda_{\mathrm{h}}=\mathrm{IP}_{\mathrm{v}}-\mathrm{HEP} \\
& \lambda_{\mathrm{e}}=\mathrm{EEP}-\mathrm{EA}_{\mathrm{v}}
\end{aligned}
$$

$\lambda_{\mathrm{h}}$ and $\lambda_{\mathrm{e}}$ can be used to estimate the charge transfer rate and balance ability. The low reorganization energy is necessary for an efficient charge transport process. In general, the smaller $\lambda_{\mathrm{e}}$ $\left(\lambda_{\mathrm{h}}\right)$ means the better electron-transporting (hole-transporting) performance. Complex 4 with the smallest $\lambda_{\mathrm{h}}(0.74 \mathrm{eV})$ has the best hole transfer ability among these studied complexes, whereas complex 1 has the best electron transporting performance due to the smallest $\lambda_{\mathrm{e}}$ value. The $\lambda_{\mathrm{h}}$ of complexes 1-4 are larger than those $\lambda_{\mathrm{e}}$, which shows that the electron-transport performance of these complexes is better than holetransporting performance. In addition, the difference between $\lambda_{\mathrm{h}}$ and $\lambda_{\mathrm{e}}$ for complex $\mathbf{3}$ is the smallest among these complexes, which can greatly improve the charge transfer balance, thus further enhancing the device performance of OLEDs.

\subsection{Absorption spectral properties}

Based on the optimized ground state structure, the absorption spectra of complexes 1-4 in $\mathrm{CH}_{2} \mathrm{Cl}_{2}$ solvent were calculated using TDDFT/PBE0 method. The absorption wavelength, oscillator strength $(f)$ and the transition properties are listed in Table S5 (ESI). $\dagger$ The absorption spectra of complexes 1-4 are shown in Fig. 5. 


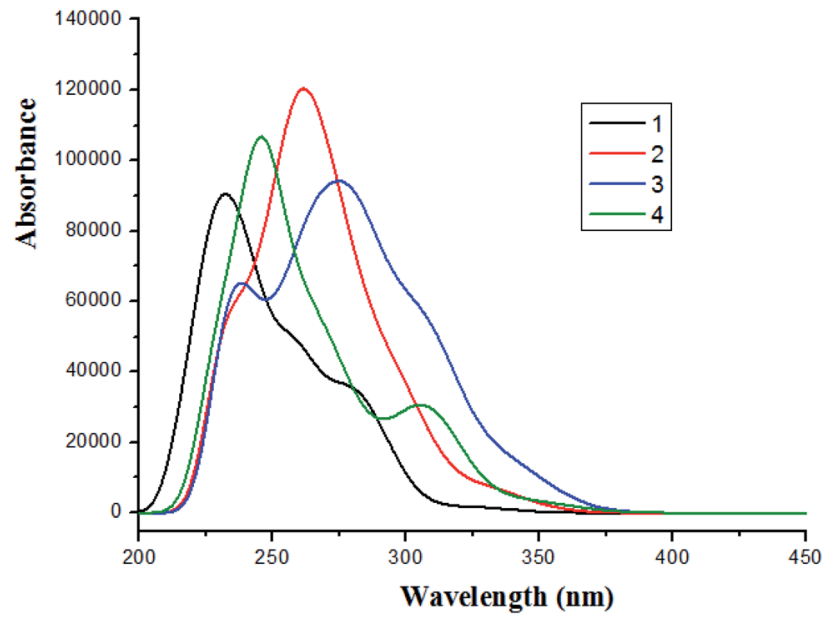

Fig. 5 Absorption spectra for in $\mathrm{CH}_{2} \mathrm{Cl}_{2}$ medium for complexes 1-4.

The lowest energy absorption wavelengths are located at $328 \mathrm{~nm}(f=0.0104)$ for $1,335 \mathrm{~nm}(f=0.0258)$ for $2,345 \mathrm{~nm}(f=$ $0.0332)$ for 3 and $347 \mathrm{~nm}(f=0.0391)$ for 4 , respectively. In contrast to 1 , the increase of conjugated degree for 2-4 leads to redshifted absorption. It can be seen form Table $55 \dagger$ that the lowest lying singlet $\rightarrow$ singlet absorption for complex $\mathbf{1}$ is comparable with the experimental value. The lowest lying transitions of complexes 1-4 are mainly attributed to the configuration of HOMO $\rightarrow$ LUMO $\left[\mathrm{d}(\mathrm{Ir})+\pi(\mathrm{L} 1) \rightarrow \pi^{*}(\mathrm{~L} 1)\right] /$ MLCT (metal to ligand charge transfer)/ILCT (intraligand charge transfer). Differently, the lowest lying transition of 4 is characterized as HOMO $\rightarrow$ LUMO (59\%) and HOMO $\rightarrow$ LUMO $+1(35 \%)\left[\mathrm{d}(\mathrm{Ir})+\pi(\mathrm{L} 1) \rightarrow \pi^{*}(\mathrm{~L} 1)\right] / \mathrm{MLCT} / \mathrm{ILCT}$. It can also be seen that the intense absorptions are in the region of wavelength $<300 \mathrm{~nm}$. For complex 3, there is a shoulder peak at about $238 \mathrm{~nm}$ wavelength.

\subsection{Phosphorescence properties}

Based on the optimized geometry of the $\mathrm{T}_{1}$ state, the emission properties of these studied complexes by the TDDFT/M052X method in $\mathrm{CH}_{2} \mathrm{Cl}_{2}$ solvent have been presented in Table 3 . The plots of the molecular orbitals related to emissions of complexes 1-4 are also provided in Fig. 6.

From Table 3, it can be seen that the calculated lowest energy emissions of complexes 1-4 are localized at 413, 550, 517 and $582 \mathrm{~nm}$, respectively. The lowest energy emission wavelength for 1 is in very good agreement with the experimental value (420 $\mathrm{nm}) .{ }^{\mathbf{1 8}}$ The lowest energy emission wavelengths of 2-4 are

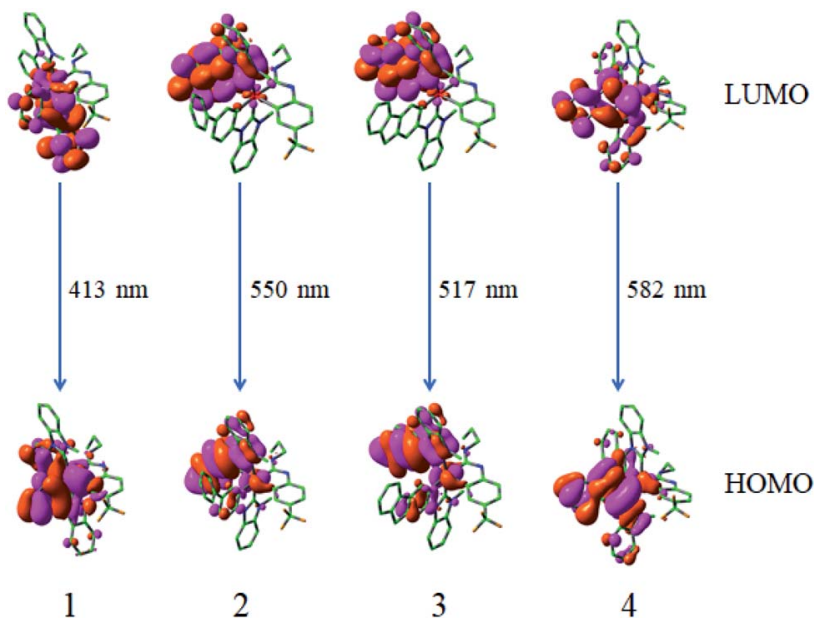

Fig. 6 Transitions responsible for the emissions at 413, 550, 517 and $582 \mathrm{~nm}$ for complexes 1-4, respectively, simulated in $\mathrm{CH}_{2} \mathrm{Cl}_{2}$ media at M052X level.

obviously redshifted in contrast to that of complex 1. The phosphorescence emissions for complexes 1-4 are mainly from the transition of LUMO $\rightarrow$ HOMO configuration, which are described as ${ }^{3}$ MLCT (triplet metal to ligand charge transfer) $/{ }^{3}$ LLCT (triplet ligand to ligand charge transfer). From Fig. 6 and Table S6, $\uparrow$ it can be seen that the LUMO distribution is mainly localized at the L1 ligand, however, the HOMO distribution is mainly at Ir d-orbitals and L1 ligand.

The emission quantum efficiency $(\Phi)$ is linked to the radiative decay rate $\left(k_{\mathrm{r}}\right)$ and nonradiative $\left(k_{\mathrm{nr}}\right)$, which can be expressed by formula (5):

$$
\Phi=k_{\mathrm{r}} /\left(k_{\mathrm{r}}+k_{\mathrm{nr}}\right)
$$

It can be seen, to increase $\Phi, k_{\mathrm{r}}$ should be increased and $k_{\mathrm{nr}}$ should be decreased simultaneously or respectively. ${ }^{35,36}$ Besides, $k_{\mathrm{r}}$ is also theoretically related to the mixing between $\mathrm{S}_{1}$ and $\mathrm{T}_{1}$, which is proportional to the spin-orbit coupling (SOC) and inversely proportional to the energy gaps between the $S_{1}$ and $T_{1}$ states according to the following formula: ${ }^{37,38}$

$$
\begin{aligned}
& k_{\mathrm{r}} \approx \gamma \frac{\left\langle\psi_{\mathrm{S}_{1}}\left|H_{\mathrm{S}_{0}}\right| \psi_{\mathrm{T}_{1}}\right\rangle^{2} \mu_{\mathrm{S}_{1}}^{2}}{\left(\Delta E_{\mathrm{S}_{1}-\mathrm{T}_{1}}\right)^{2}} \\
& \gamma=16 \pi^{3} 10^{6} n^{3} E_{\mathrm{em}}{ }^{3 / 3 h \varepsilon_{0}}
\end{aligned}
$$

Table 3 The calculated emission wavelength ( $\mathrm{nm}$ ) in $\mathrm{CH}_{2} \mathrm{Cl}_{2}$ medium at the TDDFT/M052X level for complexes 1-4, along with the major contribution and transition characters

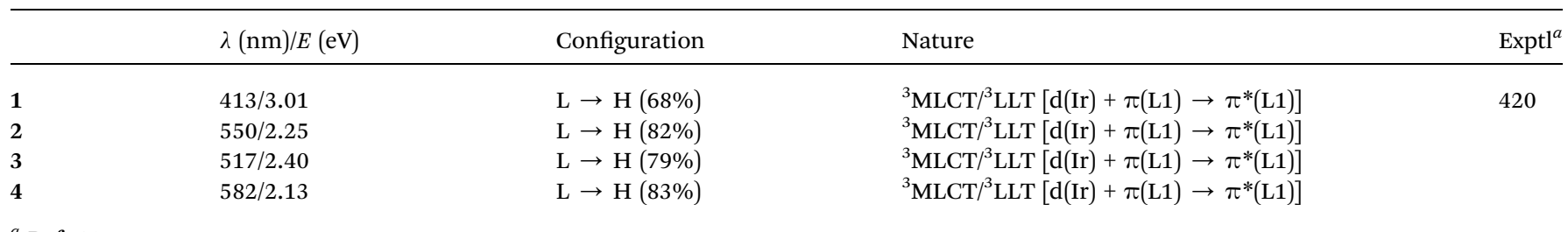

${ }^{a}$ Ref. 18 . 
where $H_{\mathrm{S}_{0}}$ is the Hamiltonian for the spin-orbit coupling, $\mu_{\mathrm{S}_{1}}$ is the transition dipole moment in the $\mathrm{S}_{0} \rightarrow \mathrm{S}_{1}$ transition, $\Delta E_{\mathrm{S}_{1}-\mathrm{T}_{1}}$ is the energy gaps between the $\mathrm{S}_{1}$ and $\mathrm{T}_{1}$ states, $E_{\text {em }}$ represents the emission energy in $\mathrm{cm}^{-1}$ and $n, h, \varepsilon_{0}$ are the refractive index, Planck's constant and the permittivity in a vacuum, respectively. Accordingly, the variation of quantum efficiency can be qualitatively analyzed in theory from the above formula. The increased ${ }^{3} \mathrm{MLCT} \%$ is in favour of enhancing the phosphorescence quantum efficiency and spin-orbit coupling (SOC). From the Table S7 (ESI), $\uparrow$ it can be seen that the calculated ${ }^{3}$ MLCT contributions are $21.76 \%, 23.78 \%, 19.75 \%$ and $11.62 \%$ for 1,2 , 3 and 4 , respectively. Besides, the phosphorescence quantum efficiencies are inversely proportional to the $\Delta E_{\mathrm{S}_{1}-\mathrm{T}_{1}}$. A small $\Delta E_{\mathrm{S}_{1}-\mathrm{T}_{1}}$ is required for enhancing the ISC rate, leading to the increased $k_{\mathrm{r}}$. According to formula (6) and Table S7, $\dagger$ a lower $\Delta E_{\mathrm{S}_{1}-\mathrm{T}_{1}}$, a larger ${ }^{3} \mathrm{MLCT}$ and a higher $\mu_{\mathrm{S}_{1}}$ may account for a larger $k_{\mathrm{r}}$ value. Hence, complexes 1 and 3 possibly possess the large $k_{\mathrm{r}}$ values among these complexes.

\section{Conclusion}

The geometrical structures, transporting abilities, absorptions, and phosphorescent properties for four iridium(III) complexes have been investigated by DFT/TDDFT. The HOMO and LUMO distribution for these studied complexes respectively possesses the same character, which indicates that the change of main ligands has not obvious effect. The complex with rigid skeletal structural main ligand will greatly improve the charge transfer balance and enhance the device performance of OLEDs. The maximum absorption peaks of complexes 1-3 are in the order of $\mathbf{1}<\mathbf{2}<3$, which is in accordance with their $\Delta E_{\mathrm{L} \rightarrow \mathrm{H}}$ values. Complexes 1 and 3 possibly have the large $k_{\mathrm{r}}$ values among these complexes. It can be seen that the modification of main ligands in the studied complexes can produce an important effect on the electronic structure and photophysical properties. Our study will be useful for the search for efficient iridium(III) phosphors in OLEDs.

\section{Conflicts of interest}

There are no conflicts to declare.

\section{Acknowledgements}

The authors are grateful for the financial aid from the Program of Science and Technology Development Plan of Jilin Province of China (Grant No. 20200201099JC) and the Science and Technology Research Project for the Thirteenth Five-year Plan of Education Department of the Jilin Province of China (Grant No. JJKH20181021KJ and JJKH20170604KJ).

\section{References}

1 B. Q. Liu, M. A. Jabed, J. L. Guo, W. Xu, S. L. Brown, A. Ugrinov, E. K. Hobbie, S. Kilina, A. J. Qin and W. F. Sun, Inorg. Chem., 2019, 58, 14377-14388.
2 D. Liu, K. Y. Sun, G. M. Zhao, J. Y. Wei, J. X. Duan, M. H. Xia, W. Jiang and Y. M. Sun, J. Mater. Chem. C, 2019, 7, 1100511013.

3 R. R. Valiev, R. M. Gadirov, K. M. Degtyarenko, D. V. Grigoryev, R. T. Nasubullin, G. V. Baryshnikov, B. F. Minaev, S. K. Pederse and M. Pittelkow, Chem. Phys. Lett., 2019, 732, 136667.

4 D. X. Ma, C. Zhang, Y. Qiu and L. Duan, Org. Electron., 2017, 42, 194-202.

5 F. F. Wei, S. L. Lai, S. N. Zhao, M. Ng, M. Y. Chan, V. W. W. Yam and K. M. C. Wong, J. Am. Chem. Soc., 2019, 141, 12863-12871.

6 W. Luo, C. Zeng, X. Q. Du, C. Q. Leng, W. Yao, H. F. Shi, X. Z. Wei, C. L. Du and S. R. Lu, J. Mater. Chem. C, 2018, 6, 4895-4902.

7 J. L. Liao, Y. Chi, C. C. Yeh, H. C. Kao, C. H. Chang, M. A. Fox, P. J. Low and G. H. Lee, J. Mater. Chem. C, 2015, 3, 4910-4920. 8 P. Gnanasekaran, Y. Yuan, C. S. Lee, X. W. Zhou, A. K. Y. Jen and Y. Chi, Inorg. Chem., 2019, 58, 10944-10954.

9 I. Taidakov, S. Ambrozevich, R. Saifutyarov, K. Lyssenko, R. Avetisov, E. Mozhevitina, A. Khomyakov, M. Khrizanforov, Y. Budnikova and I. Avetissov, J. Organomet. Chem., 2018, 867, 253-260.

10 L. Y. Hsu, D. G. Chen, S. H. Liu, T. Y. Chiu, C. H. Chang, A. K. Y. Jen, P. T. Chou and Y. Chi, ACS Appl. Mater. Interfaces, 2020, 12, 1084-1093.

11 L. Y. Hsu, Q. M. Liang, Z. H. Wang, H. H. Kuo, W. S. Tai, S. J. Su, X. W. Zhou, Y. Yuan and Y. Chi, Chem.-Eur. J., 2019, 25, 15375-15386.

12 A. K. Pal, S. Krotkus, M. Fontani, C. F. R. Mackenzie, D. B. Cordes, A. M. Z. Slawin, I. D. W. Samuel and E. Zysman-Colman, Adv. Mater., 2018, 30, 1804231.

13 S. Urinda, G. Das, A. Pramanik and P. Sarkar, Phys. Chem. Chem. Phys., 2017, 19, 29629-29640.

14 K. P. S. Zanoni and N. Y. M. Iha, Synth. Met., 2016, 222, 393396.

15 T. Guo, L. Yu, Y. Yang, Y. H. Li, Y. Tao, Q. Hou, L. Ying, W. Yang, H. B. Wu and Y. Cao, J. Lumin., 2015, 167, 179-185.

16 M. A. Baldo, S. Lamansky, P. E. Burrows, M. E. Thompson and S. R. Forrest, Appl. Phys. Lett., 1999, 75, 4-6.

17 V. Cleave, G. Yahioglu, P. Le Barny, R. H. Friend and N. Tessler, Adv. Mater., 1999, 11, 285-288.

18 H. Na, L. M. Canada, Z. L. Wen, J. I. C. Wu and T. S. Teets, Chem. Sci., 2019, 10, 6254-6260.

19 P. Hohenberg and W. Kohn, Phys. Rev., 1964, 136, B864B871.

20 C. Adamo and V. Barone, J. Chem. Phys., 1999, 110, 61586169.

21 J. P. Perdew, K. Burke and M. Ernzerhof, Phys. Rev. Lett., 1996, 77, 3865-3868.

22 J. Tomasi, B. Mennucci and R. Cammi, Chem. Rev., 2005, 105, 2999-3094.

23 P. J. Hay and W. R. Wadt, J. Chem. Phys., 1985, 82, 270-284. 24 P. J. Hay and W. R. Wadt, J. Chem. Phys., 1985, 82, 299-310. 25 Y. Y. Hu, W. Luo, C. G. Hu, Y. Wang, B. H. Tong, M. K. Fung, Y. P. Tian and Q. F. Zhang, J. Lumin., 2020, 219, 116846. 
26 C. H. Lin, J. L. Liao, Y. S. Wu, K. Y. Liao, Y. Chi, C. L. Chen, G. H. Lee and P. T. Chou, Dalton Trans., 2015, 44, 8406-8418.

27 C. H. Chang, Z. J. Wu, C. H. Chiu, Y. H. Liang, Y. S. Tsai, J. L. Liao, Y. Chi, H. Y. Hsieh, T. Y. Kuo, G. H. Lee, H. A. Pan, P. T. Chou, J. S. Lin and M. R. Tseng, ACS Appl. Mater. Interfaces, 2013, 5, 7341-7351.

28 M. J. Frisch, G. W. Trucks, H. B. Schlegel, G. E. Scuseria, M. A. Robb, J. R. Cheeseman, G. Scalmani, V. Barone, B. Mennucci, G. A. Petersson, H. Nakatsuji, M. Caricato, X. Li, H. P. Hratchian, A. F. Izmaylov, J. Bloino, G. Zheng, J. L. Sonnenberg, M. Hada, M. Ehara, K. Toyota, R. Fukuda, J. Hasegawa, M. Ishida, T. Nakajima, Y. Honda, O. Kitao, H. Nakai, T. Vreven, J. A. Montgomery Jr, J. E. Peralta, F. Ogliaro, M. Bearpark, J. J. Heyd, E. Brothers, K. N. Kudin, V. N. Staroverov, R. Kobayashi, J. Normand, K. Raghavachari, A. Rendell, J. C. Burant, S. S. Iyengar, J. Tomasi, M. Cossi, N. Rega, J. M. Millam, M. Klene, J. E. Knox, J. B. Cross, V. Bakken, C. Adamo, J. Jaramillo, R. Gomperts, R. E. Stratmann, O. Yazyev, A. J. Austin, R. Cammi, C. Pomelli, J. W. Ochterski, R. L. Martin, K. Morokuma, V. G. Zakrzewski, G. A. Voth, P. Salvador, J. J. Dannenberg, S. Dapprich, A. D. Daniels,
J. B. Foresman, J. V. Ortiz, J. Cioslowski and D. J. Fox, Gaussian 09, Gaussian Inc., Wallingford CT, 2009.

29 N. M. O'Boyle, A. L. Tenderholt and K. M. Langner, J. Comput. Chem., 2008, 29, 839-845.

30 N. S. Hush, J. Chem. Phys., 1958, 28, 962-972.

31 R. A. Marcus, Rev. Mod. Phys., 1993, 65, 599-610.

32 R. A. Marcus, J. Chem. Phys., 1956, 24, 966-978.

33 M. Malagoli and J. L. Brédas, Chem. Phys. Lett., 2000, 327, 1317.

34 B. C. Lin, C. P. Cheng, Z. Ping and M. Lao, J. Phys. Chem. A, 2003, 107, 5241-5251.

35 S. Fantacci, F. De Angelis, A. Sgamellotti, A. Marrone and N. Re, J. Am. Chem. Soc., 2005, 127, 14144-14145.

36 A. B. Tamayo, S. Garon, T. Sajoto, P. I. Djurovich, I. M. Tsyba, R. Bau and M. E. Thompson, Inorg. Chem., 2005, 44, 87238732.

37 S. Haneder, E. D. Como, J. Feldmann, J. M. Lupton, C. Lennartz, P. Erk, E. Fuchs, O. Molt, I. Münster, C. Schildknecht and G. Wagenblast, Adv. Mater., 2008, 20, 3325-3330.

38 N. Turro, Modern Molecular Photochemistry, University Science Books, Palo Alto, CA, 1991. 